The role of pre-school quality in promoting resilience in the development of young children

\author{
James Hall* \\ Kathy Sylva* \\ Edward Melhuish $^{\dagger}$ \\ Pam Sammons ${ }^{\#}$ \\ Iram Siraj-Blatchford ${ }^{\$}$ \\ Brenda Taggart ${ }^{\$}$ \\ †Birkbeck, University of London, \\ ${ }^{\#}$ University of Nottingham,
}

*Department of Education, University of Oxford,

${ }^{\$}$ Institute of Education, University of London

$\mathrm{XX} / \mathrm{X} / 2009$

Word Count: XXXX (Introduction through Discussion)

Running head: pre-school quality and resilience 


\title{
The role of pre-school quality in promoting resilience in the development of young children
}

\begin{abstract}
The study reported here investigates the role of pre-school education as a protective factor in the development of children who are at risk due to environmental and individual factors. Previous studies on resilience have found only limited support for such a protective relationship. This investigation builds upon earlier research by examining different kinds of "quality" in early education. It tests the hypothesis that pre-schools of high quality can moderate the impacts of risks upon cognitive development. If quality moderates the impact of known risks, then it can be considered an educational "protection" in child development and a promoter of resilience. Cognitive development was measured in 2857 English pre-schoolers at 36 and 58 months of age. At the same time, 22 individual risks to children's development were measured as well. The 141 pre-schools that the children attended had the quality of their provision assessed by three measures. Multilevel structural equation modelling revealed that: the global quality of pre-school can moderate the effects of familial risk (such as poverty), the relationships between staff and children can moderate the effects of child level risk (such as low birth weight), and the specific quality of curricular provision can moderate the effects of both. Policy makers need to take quality into account in their efforts to promote resilience in young 'at risk' children through early childhood services.
\end{abstract}

Keywords: child development, pre-school quality, risk, resilience $\mathrm{XX} / \mathrm{X} / 2009$ 


\section{The role of pre-school quality in promoting resilience in the development of young children}

\section{Introduction}

This study focuses on pre-school education as a means to enhance development in young, 'at risk' children. If pre-school can have a beneficial effect on children's intellectual development, then such enhanced intellectual development can contribute in important ways to wellbeing (e.g. Chase-Lansdale et al., 2003). This paper rests on the assumption that the capacity to cope with adversity depends heavily on intellectual resources. Masten (1997) summarises the contribution of intellect to children's capacity to 'respond robustly' when meeting adversity: "The most important protective resource for development is no surprise, it is a strong relationship with a competent, caring, prosocial adult. The most important individual quality is probably normal cognitive development, which has emerged as a key factor in many forms in the literature including average or better IQ scores, good attention skills, and 'street smarts.' Research shows that catastrophic stressors can threaten the integrity of a child's ability to think and solve problems; but if good parenting (by parents or others) and good cognitive development are sustained, human development is robust even in the face of adversity." (Masten, 1997; italics added)

Recent investigations into the effects of pre-school education on young children's development have shown moderate to strong effects on cognitive and social development (e.g. Sammons et al., 2007; The National Institute for Child Health and Development, NICHD, 2003a; Vandell \& Wolfe, 2000). Simultaneously, recent advances in the investigation of risk and resilience in child development have focused 
on multilevel dynamics such as those between the development of children at risk and educational provision (Masten, 2007). In uniting these two areas of research, it is not surprising that attempts have been made to investigate whether pre-school provision and primarily its quality (Luthar and Brown, 2007), can protect children's development from the impacts of risks. To date, the research that has investigated this topic has reached only limited conclusions (e.g. NICHD, 2000; Burchinal, PeisnerFeinberg, Bryant, \& Clifford, 2000). The large scale national study conducted in the U.S. by the NICHD (2000) reported their findings as being, "Contrary to expectations" due to problems with sampling and measurement of quality. This study re-examines the issues of pre-school provision and "protected" child development in a secondary analysis that makes use of some novel methods of assessing risk in its analysis.

\section{Risk, Resilience, and Protection}

For researchers investigating the development of children, risks have been defined as, "Personal and environmental factors that adversely affect growth and development" (Johnson \& Waldfogel, 2002). This conceptualization is one that researchers such as Cicchetti (2003) have built upon when making the argument that risk implies development within the context of significant adversity. Research that has investigated risks arose from the observation that some individuals who were exposed to incontrovertible adversity in their lives nevertheless achieved adaptive development (Yates, Egeland, \& Sroufe, 2003).

Although used with a variety of definitions (Luthar, Cicchetti, \& Becker, 2000a) the term 'resilience' has been argued to be inextricably linked to risk such that resilience 
is a response of overcoming, rather than succumbing, to the impacts of risks in life (see Rutter's seminal paper from 1987). Twenty years later, researchers still use Rutter's theoretical framework with authors such as Cicchetti (2003) arguing that resilience refers to processes in development that result in positive adaptation despite significant adversity.

Two mechanisms are believed to underlie the process of resilience and these have been termed 'promotive' when broadly beneficial (Sameroff, Gutman, \& Peck, 2003) and 'protective' when countering the effects of adversity and risk (Rose, Holmbeck, Coakley, \& Franks, 2004). Rutter (1987) argued that protection refers not to a universal and directly observable factor, but rather to a process or mechanism through which the detrimental developmental impacts associated with experiencing risks are mitigated to result in resilience. This particular conceptualization of resilience as a process rather than a factor complicates the identification of both protection and resilience itself (see Luthar, Cicchetti, \& Becker, 2000a, 2000b): they rely upon being indirectly inferred rather than directly measured. This inferring of protection frequently leads researchers of resilience to seek out factors that may moderate the effects of risks upon outcomes (Masten \& Powell, 2003). Should evidence of a significant moderation be found in 'surprising' developmental pathways (i.e. individuals who succeed above the odds), this is taken to imply that a protective process has been operating in the context of the risks.

\section{Effects of pre-school provision}

The contribution of pre-school education to resilience in young children's development was outlined by Yates, Egeland, and Sroufe (2003) who suggested that 
educational milieus may serve as a community level protective resource when they included nurturing and attentive adult-child relationships. A more biological stance was taken by Chryssanthopoulou, Turner-Cobb, Lucas, and Jessop (2005) who discussed the benefits of attending pre-school to young children's responses to stressful events. They proposed that early education and care is often overlooked as being able to protect development through enhancing children's abilities to cope with stressors. The authors subsequently reported that although pre-school care has the potential for negative effects (e.g. Belsky, 2001), it can also facilitate development, including mitigating the effects of familial adversity (see also Goodman \& Sianesi, 2005). Such amelioration is thought to be possible because pre-school is conceived as a social environment consisting of nested structures of social interactions ensconced within a child focused ecology (Marshall, 2004).

In investigating the impacts of pre-school on the development of young children, some have argued that the quality of provision will influence the impact of risks (e.g. Magnuson, Meyers, Ruhm, \& Waldfogel, 2004; Stipek et al., 1998). Although hotly debated within the field of early years research (Sylva et al., 2006a), the notion of 'quality' is one commonly assumed to relate to the 'structures' and educative 'processes' that make up the provision (Currie, 2001). Additionally, the associations between both types of quality (especially process) and young children's cognitive development has been identified by studies based both in the U.K. (e.g. Sylva, Melhuish, Sammons, Siraj-Blatchford, \& Taggart, 2004) as well as in the U.S. (e.g. NICHD, 2003b). Of particular concern for this investigation is whether high preschool quality could protect the cognitive development of young children deemed to be at risk. This is especially salient given the dramatic expansion of pre-school 
provision in the U.K. since 1997, part of which can be seen in the figures published by the British Government (DfES, 2006).

Most studies on the protective effects of pre-school have focused on specific interventions rather than mainstream pre-school services. Moreover, few attempts have been made to examine the relationships between different types of risk and the quality of pre-school provision. To address these gaps in the research, the NICHD (2000) investigated caregiver-child relationships and the overarching familial risks to these children's development. Although they found only limited evidence for protection, this was a finding partially attributed to their sampling procedures: they studied a small number of children who were in high quality care and yet who were at high risk for their development.

Another attempt to examine whether pre-school could protect young children's cognitive abilities was conducted by Burchinal, Peisner-Feinberg, Bryant, and Clifford (2000). The authors argued that theirs was the first study to have sampled enough children whose development was at-risk to effectively test a moderating hypothesis. They carried out a secondary analysis on a sample of over 1000 young children. Their study postulated that the relationship between the quality of pre-school and young children's developmental outcomes would vary across differing types of risks including: child gender, ethnicity, family poverty, and parental values. Measuring pre-school quality on the Early Childhood Environment Rating Scale (ECERS; Harms \& Clifford, 1980), the authors reported only one significant protective factor: high quality pre-school was found to protect the language development of children from ethnic minority backgrounds. Unpacking the possible 
reasons behind this limited evidence of protection, the lack of extensive information about families and a measure of pre-school quality that was less detailed than ideal were put forward as possible explanations.

\section{Overview of the current study}

This study reported here sampled a large group of children with multiple risks to their development, and linked these to the process quality of the pre-schools they attended. In doing so, a secondary analysis was carried out of the (anonymised) longitudinal data collected by the Effective Provision of Pre-School Education project (EPPE; see Sylva, Melhuish, Sammons, Siraj-Blatchford, \& Taggart, 2004; Siraj-Blatchford, I., Sylva, K., Melhuish, E., Sammons, P., Taggart, B. \& Jennings. R, 1999; Sammons et al., 1999) This was a longitudinal English study that began in 1997 with the aim of investigating the effects of pre-school education and care on the development of over 3,000 children between the ages of 3 and 7. These young children had their cognitive abilities measured at 36 and 58 months of age together with 22 potential risks to these abilities, and 6 measures of the process quality of the pre-schools these young children attended.

Aims of the research. The separate effects of independent overarching familial and child level risks to children's General Cognitive Abilities (GCA; Elliot, NFER-NELSON, Smith, \& McCulloch, 1996) at entry to reception were hypothesised to be moderated by the process quality of the pre-schools that they attended. Based on the findings of previous research it was assumed that the greater the process quality of the pre-school, the smaller would be the effect of risks upon young children's cognitive abilities. If evidence of moderation were found, then this would support the 
theory that young children who develop in the context of significant risk can be protected against it rather than remain solely vulnerable. In turn, any evidence of protection would suggest that these at-risk children had shown resilience to the impact of risks that might otherwise impair their development.

\section{Method}

\section{Participants}

The EPPE project. The EPPE project (1997-2003) sampled 6 types of pre-school from 6 geographical regions representative of the U.K. (covering urban, rural and suburban areas). A random sample of their children was recruited after informed consent from their parents and pre-school quality was obtained. The final sample consisted of 2,857 English children from the six most common types of early education in the UK that existed in England when the EPPE project began in 1997 (for details see Sylva et al., 1999), as well as 310 children who had not attended pre-school.

The present study examined: 1) the cognitive development of the pre-school children, 2) their demographic and family characteristics, and 3) the process qualities of the pre-schools they attended. Although this investigation concentrated on investigating the effects of the quality of the pre-schools rather than the 6 different types, variation in quality across the types of provision is an issue returned to in the discussion.

\section{Measures}

Cognitive Development. When they entered the EPPE study, the young children were assessed by trained researchers on the British Ability Scales (BAS; Elliot, NFERNELSON, Smith, \& McCulloch, 1996). This gave two composite scores, verbal and 
non-verbal. The scales were again used when children began primary school (entering reception class). The sub-scales can be relied upon to give a consistent and age appropriate assessment of children's General Cognitive Abilities (GCA; see Hill, 2005). The means and standard deviations of the GCA scores of the children at the beginning and end of this study were as follows:

- Entry to study (mean age 37 months): Mean $=91.36$, Standard Deviation $=13.9$

- Exit from study (mean age 58 months): Mean $=95.64$, Standard Deviation $=15.02$

Combined Risks. 22 potential risks were identified from the EPPE dataset and were divided into two broad categories: Individual/Child or Familial Risk. This division of risk was based on an ecological perspective and is relatively uncommon when investigating the impact of risks upon children's development (Sameroff, Gutman, \& Peck, 2003; Sameroff, Seifer, Baldwin, \& Baldwin, 1993). Child risks referred to characteristics of children themselves such as gender or low birth weight, whilst familial risks reflected a family's structure and Socio-Economic Status (SES). The twenty two risks and their categorizations are presented below (Table 1) together with references to previous studies that have established the impacts of these risks upon children's development. Descriptive statistics of both the individual and combined risks can be found in the results.

Insert Table 1 about here

The last of these potential risks, the early years Home Learning Environment (HLE) is a rating scale measure developed by the EPPE team to assess the learning opportunities available to children in their home environments (such as being read to 
by family members, being taught songs and nursery rhymes, playing with letters and numbers etc). Measurement of the HLE was based on parental responses to interview questions asked when their child entered the study. The authors have already reported that the HLE demonstrated stronger relationships with children's cognitive abilities at both baseline and at entry to reception than socio-demographic measures such as family income or the occupational status of parents (Sammons, Sylva et al., 2002; Melhuish et al., 2008).

To obtain a measure of the child risk and familial risk to young children's cognitive development (see Table 1), a Confirmatory Factor Analysis (CFA) using formative measurement was used (see Hall et al., in press; Kleine, 2006). The CFA returned a measure of combined risk that was based upon individual risks being allowed to vary in their individual contributions to the combined risk.

\section{Pre-school Provision.}

The process quality of pre-school was hypothesised to be a protective factor. A measure of process quality was achieved from the use of three instruments that assessed: the global quality, the quality of specific curricular provision, and the interactional quality (see, Sylva et al., 1999).

The Early Childhood Environmental Rating Scale Revised Edition (ECERS-R; Harms, Clifford, \& Cryer, 1998) uses a 7-point scale (7 being, "excellent") to assess seven distinct global aspects (subscales) of pre-school provision: Space and Furnishings, Personal Care Routines, Language-Reasoning, Activities, Interaction, Program Structure, and Parents and Staff. Based on the trained fieldworker's 
assessments of each subscale, a global measure of quality was obtained by taking the mean of these ratings $($ Mean $=4.47$, Standard Deviation $=1.00)$.

The Early Childhood Environmental Rating Scale Extension (ECERS-E; Sylva, SirajBlatchford, \& Taggart, 2006) was developed by EPPE to assess the curricular provision of the English Foundation Stage Curriculum (DfEE, 2000). Adopting the same structure as the ECERS-R, the ECERS-E consists of four 7 point subscales: Literacy, Mathematics, Science, and Environment and Diversity. The overall quality of educational provision was measured by taking the mean of each subscale (Mean $=$ 3.27, Standard Deviation $=1.01$ ).

The last of the instruments used in this study to assess process quality was the Caregiver Interaction Scale (CIS; Arnett, 1989), a 4-point scale (4 being “very much characteristic") assessed the interactions of caregiving staff with children in their care. The CIS is made up of 26 items and 4 factors that assess different areas of caregiverchild relationships: Positive, Punitive, Permissive, Detached. The CIS was not used as a single measure but rather at the individual factor level in this study. This decision was based upon the observation that many definitions of process quality give particular emphasis to the interaction of staff with children (e.g. Espinosa, 2002). The means and standard deviations of each of the CIS factors were as follows:

- Positiveness: Mean $=3.30$, Standard Deviation $=0.50$

- Punitiveness: Mean $=1.45$, Standard Deviation $=0.25$

- Permissiveness: Mean $=1.46$, Standard Deviation $=0.41$

- Detachment: Mean $=1.41$, Standard Deviation $=0.49$ 
Analyses

The analyses were shaped by several considerations that originated from both the research literature on resilience and from the nature of this investigation and its dataset. Unlike previous studies of risk and resilience this analysis derived combined measures of risk that where differentiated according to their ecological levels. An attempt was made to demonstrate protection through statistically significant multiplicative interaction terms of the form: Risk $x$ Protection. At the same time, the nature of the research questions and the EPPE dataset also served to shape these analyses. This included the need to take into consideration the nesting of children within pre-schools, missing data imputation as attrition is a particular problem for longitudinal studies (Goldstein, 1979), and the explicit adoption of a developmental perspective. The last of these, the developmental perspective, was achieved by the analyses taking into account both children's General Cognitive Abilities (GCA) when they entered the EPPE study and the impacts that risks might already have had prior to the children beginning pre-school. In attempting to take these considerations into account, Structural Equation Modelling (SEM) was used (see Figure 1).

Insert Figure 1 about here

Figure 1 is a stylised representation of the analyses used in this investigation:

Structural Equation Models (SEM) using the Mplus statistical package (Muthén \& Muthén, 2004) were used to examine the relationships between child and familial risks, General Cognitive Abilities (GCA), and the process quality of pre-schools. A series of analyses were conducted in which each measure of process quality was examined independently to see whether it moderated the effects of the risks. In other 
words, did the continuum of low-to-high quality affect at-risk children more than it affected low-risk children? To test these hypotheses of risk moderation, multiplicative interaction terms were used of the form: process quality $x$ risk.

Due to the nesting of children within pre-schools, the data analysed in this investigation are said to be multi-level (or hierarchical) and the Structural Equation Modelling illustrated in Figure 1 took this nesting into account in order to obtain results that were of greater validity for interpretation. This was ensured by correcting the standard errors of the regression and correlation coefficients using a statistical procedure known as 'aggregated modelling' (see Asparouhov, 2005; Muthén \& Muthén, 2007).

In attempting to further ensure validity, two other analytical procedures were also used. The first of these was imputing the missing data using the robust Maximum Likelihood (MLR) algorithm which has been shown to be a reliable estimator (see Enders, 2001; Yuan \& Bentler, 2000). The second concerned the use of multiplicative interaction terms and required that the variables that were to be multiplied together were first zero-centred about their means (McCartney, Burchinal, \& Bub, 2006; Wu \& Zumbo, 2007).

\section{Results}

Descriptive Statistics.

Table 2 presents a description of the seven variables that this study conceptualised as posing child level risks to young children's cognitive development. Of all the variables presented, birth weight can be seen to have a much larger variance than the 
others due to its scale. This was a serious problem for the subsequent analyses because when variables are measured differently, with some having variances outside the range 1-10, convergence problems often appear with the MPLUS software (Muthén \& Muthén, 1998-2001). To solve both this problem and that of the necessary mean-centring of variables to be used in interaction terms, it was therefore decided to z-score all variables a priori. Finally, in order to simplify the confirmatory factor analysis part of the subsequent analyses, the categorical variable that recorded children's ethnicity was dummy-coded into six dichotomous variables with "White" serving as the reference category (see Hardy, 1993).

Insert Table 2 about here

Like Table 2, Table 3 also contains a description of variables that this study hypothesised as posing risks to young children's cognitive development. However, unlike Table 2, Table 3 reports on fourteen variables that this study conceived of working together to form a combined familial level of risk. As with the child level risks, not all risks were measured on a similar scale (family salary and HLE) which served as a reason to z-score all the variables prior to the Structural Equation Modelling.

Insert Table 3 about here

\section{Multilevel Structural Equation Modelling}

Model Fit. Although Structural Equation Modelling typically includes estimates of how closely the hypothesised models fitted the data (e.g. the Comparative Fit Index, CFI; Bentler, 1990), these indices were not always possible to obtain in this series of 
analyses. When latent interaction terms were statistically examined (latent risk $\mathrm{x}$ observed pre-school quality) the Mplus package is unable to calculate fit indices other than those used solely for model selection (e.g. the Akaike Information Criterion (AIC; Akaike, 1974). As a result, when it came to analyzing the results of models featuring latent interaction terms, there was no empirical evidence to rely upon in determining how successful a given model was in replicating the data that were used within it. However, the use of these indices as an indicator of model validity has been cautioned against by Kenny (2008) and this supports the argument that the lack of fit indices does not necessarily prohibit an interpretation of the results.

Risk Factor Loadings. The first pair of analyses undertaken was an independent assessment of the combined child and familial risks, their composition, and their effects upon young children's General Cognitive Abilities (GCA). Table 4 presents the results of these analyses with both the formative factor loadings and the effects of each latent combined risk to GCA being equivalent to beta regression coefficients. The stylised SEM of Figure 1 (minus the qualities of the pre-schools) illustrates these separate analyses.

Insert Table 4 about here

Examining the factor loadings in Table 4 reveals the differences between, and relative sizes of, the contributions that each observed risk made in forming a latent combined risk. For child level risks, statistically significant risks included: child gender; birth weight; no. of siblings; and coming from an ethnic minority (excluding Indian or "other"). However, the risk that most strongly contributed to a combined latent 
measure was speaking English as an additional language (EAL; 0.48). This combined child level risk was, in turn, highly predictive of the GCA of young children at both entry to pre-school and reception. Furthermore, the effect at entry to reception was found over and above the effect of GCA at entry to pre-school $(\beta=0.67, p<0.001)$. This total model was found to explain $52 \%$ of the variation in young children's GCA scores at entry to reception.

In considering familial risks, similar and stronger effects to those identified with child level risks were again found. Statistically significant risks included: Family salary; mother's occupational status and formal qualifications; whether or not her partner was employed; the number of non-parental carers; and the Home Learning Environment. In addition, the combined familial level risk significantly predicted lower levels of GCA at both entry to pre-school and reception that was over and above the effect of GCA on itself between these two periods $(\beta=0.59, p<0.001)$.

Although these analyses only varied from one another in the measures of risk that were examined, substantial differences were then observed between the fit indices of the two models. For the child level analysis, the CFI was close to its upper limit of 1 (0.99), as was the Tucker-Lewis Index (0.98; TLI, Bentler \& Bonett, 1980) whilst the Root Mean Square Error of Approximation (RMSEA) was within a range that has been associated with a high degree of model fit (0.03; see Browne \& Cudeck, 1993). Conversely, the values of these indices were found to be much lower for the analysis of the familial level risk: $\mathrm{CFI}=0.32 ; \mathrm{TLI}=0.14$; $\mathrm{RMSEA}=0.14$ which suggests the results of all the familial analyses therefore need to be read with caution. The familial models are less powerful at predicting risks and their developmental consequences. 
Pre-school influencing and protecting young children's General Cognitive Abilities

Table 5 presents the direct and risk-moderating effects of the process quality of pre-schools upon young children's GCA at entry to reception. Of the six measures of process quality within pre-schools, four were found to significantly moderate the impacts of risks upon young children's General Cognitive Abilities (GCA) at school entry whilst taking into account these abilities at entry to pre-school. The significant moderators were identified as: the global quality of the pre-school, curricular quality, and the degree to which the staff-child interactions could be characterised as positive and/or non-detached (interactional quality).

The results that are presented in Table 5 take the form of $u n$ standardised beta regression coefficients because the majority of the values within this table are multiplicative statistical interaction terms (risk $x$ quality). When interpreting and reporting statistical relationships that involve these terms it is common practice to report only the unstandardised values (Baron \& Kenny, 1986; Tabachnick \& Fidell, 2001). Furthermore, to ease the comparison of direct and moderating effects, the direct effects of quality are also given in this unstandardised form. Importantly though, the z-scoring of these variables that was carried out a priori led to a consistent within variable metric: each unstandardised beta coefficient presented in Table 5 is in the form of standard deviations. This is the procedure suggested by Tabachnick and Fidell (2001) for obtaining standardised results when reporting interaction terms (see also Friedrich, 1982). 
In addition to moderations of risks, Table 5 also documents the direct effects of process quality upon the development of young children's GCA at entry to school. However, these results varied given the nature of the risk under examination with the effects appearing to lessen in the context of familial rather than child level risks. Under the context of child level risk, both permissiveness and detachment can be seen to have the largest direct effects, both in a negative direction $(\beta=-0.05, p<0.05$ and $\beta$ $=-0.06, p<0.01$ respectively). However, when these same relationships are examined in the context of familial risk, the quality of staff-child relationships no longer appear significant. These discrepancies reveal the importance of studying different kinds of risk in these analyses, especially given the large relationships that were previously observed between each combined risk and young children's GCA.

Insert Table 5 about here

Although Table 5 reveals that the quality of the curricular provision had the broadest range of significant risk moderations for both familial $(\beta=0.03, p<0.001)$ and child level risk $(\beta=0.02, p<0.05)$, the promotion it appeared to confer was not the greatest in magnitude. Instead this effect was found to be associated with child level risk and the detached interactions between caregiving staff and children $(\beta=-0.06, p<0.01)$. Although these Beta effects are small, they are statistically significant unstandardised coefficients which are of similar size to those of the main direct effects of quality. This similarity in size is especially surprising considering that Luthar argues that interaction terms in resilience studies, “...typically have small effect sizes” (Luthar, 2006) 
The significant moderating relationships between the process qualities of pre-school and risks presented in Table 5 are illustrated in Figures 2 and 3. Together, these two figures demonstrate that as the process quality of a pre-school increased, so the relationship between risk and development decreased. All of these graphs show that GCA falls sharply for all children as risks increase. However, the fall in GCA is lower for children who had experienced high quality provision, demonstrating that quality of provision appears to "protect" children from the sharpest falls in GCA related to their risk factors. This protection may also be interpreted as the high quality pre-school providing a cognitive 'boost' above that predicted by background and fits with earlier findings reported by Sammons, Sylva, and colleagues (2002) that showed significant variation in pre-school effectiveness (value added) and that pre-school quality was a significant positive predictor of variations in children's cognitive progress during their time in pre-school.

Insert Figure 2 about here

Insert Figure 3 about here

\section{Discussion}

The above results clearly indicate that for children whose development could be thought of as at-risk, attending pre-schools of high process quality appeared to mitigate the impacts of these risks. In turn, this can be taken as evidence that attending high quality pre-school care can protect young children's cognitive development and thus contribute to them displaying resilience to risks. Maintaining the ecological perspective adopted by this study, these results and their implications 
are now discussed across three levels pertaining to: children, pre-schools, and the wider communities that both are nested within.

\section{Young children's cognitive development}

This study clearly confirmed the hypothesised impacts of those variables identified as risks upon young children's development and therefore their future well-being. Furthermore, the relatively large differences in the size of the impacts that were observed for each measure of combined risk justified the Confirmatory Factor Analysis (CFA) strategy that was employed. Given that a strategy of examining individual risks had been cautioned against in earlier research (e.g. Burchinal, Roberts, Hooper, \& Zeisel, 2000), the CFA procedure revealed the circumstances and characteristics that were, on average, associated with significantly lower General Cognitive Abilities (GCA) at entry to primary school. The children who displayed many of the individually identified risks were found to have a GCA at entry to reception around 2 standard deviations lower than the sample average, lower than approximately $97 \%$ of the sample.

Figures 2 and 3 illustrate the protective effects that were indicated by this study: the effects of a risk on General Cognitive Ability decreased as a protective effect increased in magnitude. Moreover, Figures 2 and 3 revealed that in this investigation, the nature of this risk-protection seemed to vary with the nature of the protection (the quality) being examined. Whilst the effects of a more proximal (to the child) child level risk appeared to have been protected against by the more proximal (to the child) staff-child interactions, the more distal familial level combined risk appeared to have been protected against by the more distal global quality of pre-school (with curricular 
provision protecting against both). These findings offer support to those theoretical frameworks of resilience that argue for an incorporation of both the influences of distal and proximal influences on children's development (Kaplan, 1999; Luthar, Cicchetti, \& Becker, 2000a).

The results of this study also differ markedly from those cited at the beginning of this paper (Burchinal, Peisner-Feinberg, Bryant, \& Clifford, 2000; NICHD, 2000) which found only limited support for the view that pre-school can protect young children's development. There are a number of factors that might explain this with the first concerning the different size of the samples. Whilst the studies conducted by the NICHD had a sample of 943 children and the Burchinal et al. study 1,307, this investigation studied a much greater sample of 2,857 . Indeed, the study conducted by Burchinal and colleagues itself noted that in quantitative analysis, insufficient sample size often limits the knowledge that can be gained and that this is exacerbated when attempting to detect statistically significant moderation effects. With its larger sample size, this study therefore had a greater capacity to detect whether the quality of pre-school could be a statistically significant moderator of the impacts of risks.

In addition to the differences in sample size, this study also differed from those of the NICHD (2000) and Burchinal, Peisner-Feinberg, Bryant, and Clifford (2000) in the measurement of the process quality of pre-schools. Whilst the above studies each included only a single measure of process quality, this investigation included six and found noticeable differences between their abilities to moderate the impacts of risk. By this more detailed measurement of quality (and with larger numbers of children in each of the 141 pre-school settings in the clustered sample), this study identified 
patterns of protection not seen in these earlier studies and that are best illustrated with a comparison. The study conducted by the NICHD included a measure of quality that was broadly analogous to the Caregiver Interaction Scale (CIS) that was used here in that it attempted to measure a caregiver's detachment, positive regard, and responsiveness. Furthermore, the NICHD study also examined a series of measures that they termed "family risk" and found that their CIS analogous measure was not broadly protective against the impacts of this risk. Their findings are mirrored here (see Table 5) but also extended, in that the caregiving relationships examined in this study were found to significantly moderate the impacts of child level risks but not familial ones.

\section{Processes and activities in pre-school provision}

The curriculum and activities that take place within a pre-school were identified by this study as offering significant protection to the well being and development of the cognitive abilities of young children that were 'at risk'. The relationships between caregivers and staff appeared to be of particular importance in the context of child level risks, whilst the overall quality of a pre-school was found especially important in the context of family level risks. For both kinds of risk, however, this study has shown that children's development was partially protected by attendance at a pre-school with high quality curricular provision.

A comparison against programmes of Early Intervention provides some explanation as to why it was that certain qualities of pre-school seemed to be able to protect young children's development. Sylva (2000) identified similarities in both the forms and impacts of high quality Early Interventions and mainstream pre-school provision. 
When they are of a high quality, both have been found to prevent the outcomes of school failure and poor adjustment that have been associated with development in the context of social disadvantage (e.g. Campbell \& Ramey, 1994; Sammons, Taggart et al., 2002). As a result, Sylva makes the argument that programmes of pre-school education have the potential to serve as interventions with normal populations by serving as a type of primary prevention. This comparison also suggests why it was that integrated centres that combined care with education were found to offer, on average, the highest quality of provision that might protect against the impacts of risks (Sylva, Melhuish, Sammons, Siraj-Blatchford, \& Taggart, 2004). The integration of child care and early education, as in Early Interventions, was aimed at supporting families and even influenced the creation of the Children's Centres that are integral to the UK Sure Start programme (Tunstill, Allnock, Akhurst, \& Garbers, 2005).

Designed to prevent the social exclusion of children who live in poverty through community targeted intervention, Sure Start aims to provide early years services that integrate early education and child care (Brown \& Dillenburger, 2004; DfES, 2003) in the same manner as those centres which the EPPE team found to provide the highest quality care and education.

\section{Combating social inequalities in society}

Although this study indicated that pre-school might be able to protect the general cognitive abilities of young children, the beneficial consequences of this protection to future development and well being must not be assumed. Just because young children who attended high quality pre-schools were found to have higher than otherwise anticipated cognitive abilities does not automatically mean that this will go on to benefit the children in the long term. Luthar, Cicchetti, and Becker (2000a) explicate: 
developmental skills and abilities do not facilitate adaptive development by themselves. Rather, it is instead through these skills being at first protected before then being utilised within the wider environment or community (see also Luthar, 2006; Schoon et al., 2002). As a result, the long term benefits of the protection indicated by this study should not be assumed, especially if children develop within a disadvantaged community. Previous research has indicated that 'normal' cognitive development is perhaps the single most important protective factor that a child can exhibit (Masten, 1997). Nonetheless, recent EPPE 3-11 research results for this sample indicate that the quality of pre-school provision continues to predict better academic and social behavioural outcomes at ages 10 and 11 (Sammons et al., 2008).

The results of this study lend support to those state funded social policies and programmes that have attempted to increase the quality of pre-school (e.g. the UK Childcare Act 2006). Magnuson, Ruhm, and Waldfogel (2004) identified especially large effects of attending the US programme Head Start for 'disadvantaged' children raised under conditions of social inequality. This study builds upon such work by differentiating the impacts of different markers of social disadvantage upon young children's development. It is one of the findings of this study that the social risks with the largest impacts come not from indicators of disadvantage or inequality themselves (family salary, education, occupational status), but rather less stimulating learning activities that parents undertook with their children (their Home Learning Environments).

\section{Limitations}


Despite the evidence of partial protection that was found by this study, it also had a somewhat limited scope by focusing on young children's cognitive abilities and the process qualities of pre-schools alone. Although the original EPPE studies also investigated young children's behaviour/social skills and the structural qualities of pre-school, neither of these were examined in this investigation. Instead, the focus on process quality and cognitive development was influenced by previous studies in this area such as those of the NICHD (2000) and Burchinal, Peisner-Feinberg, Bryant, and Clifford (2000) that studied the caregiving environment (ORCE, NICHD, 1996) and overall quality (ECERS) respectively. However, a wider range of developmental outcomes is needed to gain a fuller understanding of the nature of the protection high quality pre-school can offer to the development of young children.

In addition, this study also made no attempt to investigate how the protective impacts it identified varied across different types of pre-school provision. This is especially salient given that there is a widely understood relationship (e.g. Villalón, Suzuki, Herrera, \& Mathiesen, 2002) between quality and types of provision (e.g. Vandell \& Wolfe, 2000). Together, these observations indicate that the protective effect offered by high quality pre-school provision could be missed out upon by those who could benefit most if they are not enrolled in the type of provision that has the highest quality.

Another limitation of this investigation concerned the young children who were sampled in the original EPPE project. The protection afforded by quality may differ in very high risk populations, especially if their development is at risk due to variables not measured in this study. For example, can high quality pre-school aid in mitigating 
the impacts of risks upon the development of young children with physical disabilities?

\section{Future Directions}

Based on the observations that positive adaptation during early childhood is related to subsequent further positive development (e.g. Egeland, Carlson, \& Sroufe, 1993), the protection that has been indicated in this study has the potential to have further, albeit indirect, protective effects as the children grow up. The work of Masten and Powell (2003) gives an indication as to why this might be: cognitive abilities such as IQ scores, attention, and executive functioning are themselves attributes of individuals that are often associated with resilience. Consequently, by enhancing these abilities, pre-school may be promoting the future resilience of young children's development against the impacts of risks both historical and current.

Alternatively, research on pre-school intervention programmes has to date revealed that, although short term cognitive gains can be made, the effects are usually short lived as the exposure to such an enriched environment is relatively brief (Curtis \& Nelson, 2003). The authors note that longer lasting protective effects can only be expected from these programmes if they run for an extended period. Such findings have relevance for those of this investigation; the duration of the protective effects identified here may depend on the subsequent quality of the primary school education the children are enrolled in. Alternatively, authors such as Yates, Egeland, and Sroufe (2003) have argued that although early resilience may not always be apparent, it will not be 'extinguished'. Determining whether or not this is the case with the relationships observed in this study is a challenge for future research. 


\section{Acknowledgements}

This research was supported by grants from the UK Department for Education and Skills (DfES, now called the Department for Children, Schools, and Families) and the Economic and Social Research Council (ESRC). We are especially grateful to the Effective Pre-School, Primary, and Secondary Education (EPPSE) 3-14 team, the children and families who participated in this study, and the (then) DfES for granting us permission to use their data. 


\section{Correspondence to}

James Hall, Department of Education, University of Oxford, 15 Norham Gardens,

Oxford, OX2 6PY, UK Phone: +44(0)1865 274046; Fax: +44(0)1865 274144; E-mail:

James.Hall@Education.ox.ac.uk

\section{Notes on Contributors}

James Hall is a D.Phil student at the Department of Education, University of Oxford

Kathy Sylva is a Professor of Educational Psychology at the Department of Education,

University of Oxford and a Principal Investigator of the EPPE project and its ongoing extension, the Effective Pre-School, Primary and Secondary Education Project (EPPSE 3-14)

Professor Edward Melhuish is a developmental psychologist who is currently Executive Director of the National Evaluation of Sure Start. He is a Principal Investigator of the EPPE project and its ongoing extension, the Effective Pre-School, Primary and Secondary Education Project (EPPSE 3-14)

Pam Sammons is a Professor of Education at the University of Nottingham and a Principal Investigator of the EPPE project and its ongoing extension, the Effective Pre-School, Primary and Secondary Education Project (EPPSE 3-14)

Iram Siraj-Blatchford is Professor of Early Childhood Education at the Institute of Education, University of London and is a Principal Investigator of the EPPE project and its ongoing extension, the Effective Pre-School, Primary and Secondary Education Project (EPPSE 3-14)

Brenda Taggart is a Principal Investigator of the EPPE project and a Principal Investigator and the Research Co-ordinator of its extension, the Effective Pre-School, Primary and Secondary Education Project (EPPSE 3-14) 


\section{References}

Akaike, H. (1974). A new look at the statistical model identification. IEEE Transactions on Automatic Control, 19(6), 716-723.

Arnett, J. (1989). Caregivers in day care centres: Does training matter? Journal of Applied Developmental Psychology (10), 541-552.

Asparouhov, T. (2005). Sampling Weights in Latent Variable Modeling. Structural Equation Modeling, 12, 411-434.

Baron, R. M., \& Kenny, D. A. (1986). The moderator-mediator variable distinction in social psychological research: conceptual, strategic, and statistical considerations. Journal of Personality and Social Psychology, 51, 1173-1182.

Belsky, J. (2001). Emanuel Miller lecture - Developmental risks (still) associated with early child care. Journal of Child Psychology and Psychiatry and Allied Disciplines, 42(7), 845-859.

Bentler, P. M. (1990). Comparative Fit Indexes in Structural Models. Quantitative Methods in Psychology, 107(2), 238-246.

Bentler, P. M., \& Bonett, D. G. (1980). Significance Tests and Goodness of Fit in the analysis of Covariance Structures. Psychological Bulletin, 88(3), 588-606.

Brooks-Gunn, J., Han, W. J., \& Waldfogel, J. (2002). Maternal Employment and Child Cognitive Outcomes in the First Three Years of Life: The NICHD Study of Early Child Care Child Development, 73(4), 1052-1072.

Brown, E. A., \& Dillenburger, K. (2004). An Evaluation of the Effectiveness of Intervention in Families with Children with Behavioural Problems within the Context of a Sure Start Programme. Child Care in Practice, 10(1), 63-77.

Browne, M. W., \& Cudeck, R. (1993). Alternative Ways of Assessing Model Fit. In K. A. Bollen \& J. S. Long (Eds.), Testing Structural Equation Models (pp. 136-162). CA: Sage.

Burchinal, M. R., Peisner-Feinberg, E., Bryant, D. M., \& Clifford, R. (2000). Children's social and cognitive development and child-care quality: Testing for differential associations related to poverty, gender, or ethnicity. Applied Developmental Science, 4(3), 149-165.

Burchinal, M. R., Roberts, J. E., Hooper, S., \& Zeisel, S. A. (2000). Cumulative Risk and Early Cognitive Development: A Comparison of Statistical Risk Models. Developmental Psychology, 36(6), 793-807.

Campbell, F. A., \& Ramey, C. T. (1994). Effects of early intervention on intellectual and academic-achievement - a follow-up-study of children from low-income families. Child Development, 65(2), 684-698.

Chase-Lansdale, P. L., Moffitt, R. A., Lohman, B. J., Cherlin, A., Coley, R. L., Pittman, L. D., et al. (2003). Mothers' Transitions from Welfare to Work and the Well-Being of Preschoolers and Adolescents. Science, 299(5612), 15481552.

Childcare Act. (2006). Retrieved 13/05/2008. from http://www.opsi.gov.uk/acts/acts2006/pdf/ukpga_20060021_en.pdf.

Chryssanthopoulou, C. C., Turner-Cobb, J., Lucas, A., \& Jessop, D. (2005). Childcare as a Stabilizing Influence on HPA Axis Functioning: A Reevaluation of Maternal Occupational Patterns and Familial Relations. Developmental Psychobiology, 47(4), 354-368.

Cicchetti, D. (2003). Forward. In S. S. Luthar (Ed.), Resilience and Vulnerability: Adaptation in the Context of Childhood Adversities (pp. xix- xxxi). Cambridge: Cambridge University Press. 
Currie, J. (2001). Early Childhood Education Programs. The Journal of Economic Perspectives, 15(2), 213-238.

Curtis, W. J., \& Nelson, C. A. (2003). Toward Building a Better Brain:

Neurobehavioural Outcomes, Mechanisms, and processes of Environmental Enrichment. In S. S. Luthar (Ed.), Resilience and Vulnerability: Adaption in the Context of Childhood Adversities (pp. 463-488). Cambridge: Cambridge University Press.

DfEE. (2000). Curriculum guidance for the foundation stage. Retrieved 14/5/2008. from

http://www.standards.dfes.gov.uk/eyfs/resources/downloads/5585_cg_foundat ion_stage.pdf.

DfES. (2003). Sure Start Guidance 2004-2006: Overview and local delivery arrangements. Retrieved 13/05/2008. from http://www.surestart.gov.uk/_doc/P0000377.pdf.

DfES. (2006). Provision for children under five years of age in England. Retrieved $13 / 05 / 2008$. from http://www.dfes.gov.uk/rsgateway/DB/SFR/s000674/SFR32-2006.pdf.

Egeland, B., Carlson, E., \& Sroufe, A. (1993). Resilience as process. Development and Psychopathology, 5, 517-528.

Elliot, C. D., NFER-NELSON, Smith, P., \& McCulloch, K. (1996). British Ability Scales Second Edition (BAS II). Windsor: NFER-NELSON.

Enders, C. K. (2001). A Primer on Maximum Likelihood Algorithms Available for Use With Missing Data. Structural Equation Modeling, 8(1), 128-141.

Espinosa, L. M. (2002). High-Quality Preschool: Why We Need It and What it Looks Like. Preschool Policy Matters(1).

Fawcett, A. J., \& Lynch, L. (2000). Systematic Identification and Intervention for Reading Difficulty: Case Studies of Children with EAL. Dyslexia, 6, 57-71.

Friedrich, R. G. (1982). In defense of multiplicative terms in multiple regression equations. American Journal of Political Science, 26(797-833).

Goldstein, H. (1979). The Design and Analysis of Longitudinal Studies. London: Academic Press.

Goodman, A., \& Sianesi, B. (2005). Early Education and Children's Outcomes: How Long Do the Impacts Last? Fiscal Studies, 26(4), 513-548.

Hack, M., Flannery, D. J., Schluchter, M., Cartar, L., Borawski, Elaine;, et al. (2002). Obstetrical \& Gynecological Survey Outcomes in Young Adulthood for VeryLow-Birth-Weight Infants. Obstetrical \& gynecological survey, 57(6).

Hall, J. E., Sammons, P., Sylva, K., Melhuish, E., Taggart, B., Siraj-Blatchford, I., Smees, R. (in press). Measuring the combined risk to young children's cognitive development: An alternative to cumulative indices. British Journal of Developmental Psychology.

Hardy, M. A. (1993). Regression with Dummy Variables. Newbury Park, Calif: Sage.

Harms, T., \& Clifford, R. (1980). The early childhood environment rating scale. New York: Teachers College Press.

Harms, T., Clifford, R., \& Cryer, D. (1998). Early Childhood Environment Rating Scale, Revised Edition. New York: Teachers' College Press.

Hernandez. (1997). Child Development and the Social Demography of Childhood. Child Development, 68(1), 149-169.

Hill, V. (2005). Through the Past Darkly: A Review of the British Ability Scales Second Edition. Child and Adolescent Mental Health, 10(2), 87-98. 
Hogan, A. E., Scott, K. G., \& Bauer, C. R. (1992). The Adaptive Social-Behavior Inventory (ASBI) - A new assessment of social competence in high-risk 3year-olds. Journal of Psychoeducational Assessment, 10(3), 230-239.

Johnson, E. I., \& Waldfogel, J. (2002). Children of incarcerated parents: Cumulative risk and children's living arrangements. Joint Center for Poverty Research Working Paper 306: Northwestern University/University of Chicago.

Kaplan, H. B. (1999). Toward an understanding of resilience: A critical review of definitions and models. In M. D. Glanz \& J. R. Johnson (Eds.), Resilience and development: Positive life adaptations (pp. 17-83). New York: Plenum.

Kenny, D. A. (2008). Measuring Model Fit. Retrieved 17/5/2008, from http://davidakenny.net/cm/fit.htm

Kleine, R. (2006). Formative Measurement and Feedback Loops. In G. R. Hancock \& R. O. Mueller (Eds.), Structural Equation Modelling: A Second Course. Greenwich, CT: Information Age Publishing.

Luthar, S. S. (2006). Resilience in development: A synthesis of research across five decades. In D. Cicchetti \& D. J. Cohen (Eds.), Developmental psychopathology: Risk, disorder, and adaptation (2nd ed., pp. 739-795). New York: Wiley.

Luthar, S. S., \& Brown, P. J. (2007). Maximizing resilience through diverse levels of inquiry: Prevailing paradigms, possibilities, and priorities for the future. Development and Psychopathology, 19(3).

Luthar, S. S., Cicchetti, D., \& Becker, B. (2000a). The Construct of Resilience: A Critical Evaluation and Guidelines for Future Work. Child Development, 71(3), 543-562.

Luthar, S. S., Cicchetti, D., \& Becker, B. (2000b). Research on Resilience: Response to Commentaries. Child Development, 71(3), 573-575.

Magnuson, K. A., Meyers, M. K., Ruhm, C. J., \& Waldfogel, J. (2004). Inequality in Preschool Education and School Readiness. American Educational Research Journal, 41(1), 115-157.

Magnuson, K. A., Ruhm, C. J., \& Waldfogel, J. (2004). Does Prekindergarten Improve School Preparation and Performance? NBER Working Paper Series Retrieved 22/05/2008, from http://www.nber.org/papers/w10452.pdf

Marshall, N. L. (2004). The Quality of Early Child Care and Children's Development. Current Directions in Psychological Science, 13(4), 165-168.

Marsiglio, W., Amato, P., Day, R. D., \& Lamb, M. E. (2000). Scholarship on Fatherhood in the 1990s and Beyond. Journal of Marriage and Family, 62(4), 1173-1191.

Masten, A. S. (1997). Resilience in Children at-Risk. Resiliency - A Paradigm Shift for Schools Retrieved 21/3/2007, from http://www.education.umn.edu/carei/Reports/Rpractice/Spring97/resilience.ht $\mathrm{ml}$

Masten, A. S. (2007). Resilience in developing systems: Progress and promise as the fourth wave rises. Development and Psychopathology, 19(3), 921-930.

Masten, A. S., \& Powell, J. L. (2003). A Resilience Framework for Research Policy, and Practice In S. S. Luthar (Ed.), Resilience and Vulnerability: Adaptation in the Context of Childhood Adversities (pp. 1-25). Cambridge: Cambridge University Press.

Matthijs, K. (1994). Mother's occupational status and children's schooling. American Sociological Review, 1994(59), 2. 
McCartney, K., Burchinal, M., \& Bub, K. L. (2006). Contemporary Advances and Classic Advice for Analyzing Mediating and Moderating Variables. In W. F. Overton (Ed.), Best Practices in Quantitative Methods for Develomentalists (Vol. 71). Boston: Blackwell Publishing.

Melhuish, E. C., Phan, M. B., Sylva, K., Sammons, P., Siraj-Blatchford, I., \& Taggart, B. (2008). Effects of the Home Learning Environment and Preschool Center Experience upon Literacy and Numeracy Development in Early Primary School. Journal of Social Issues, 64(1), 95-114.

Muthén, L. K., \& Muthén, B. O. (1998-2001). Mplus User's Guide (Second ed.). Los Angeles, CA: Muthén \& Muthén.

Muthén, L. K., \& Muthén, B. O. (2004). Mplus user's guide. Los Angeles: Authors.

Muthén, L. K., \& Muthén, B. O. (2007). Multilevel Analysis with Latent Variables using Mplus, Institute of Education, London.

NICHD. (1996). Characteristics of infant care: Factors contributing to positive caregiving. Early Childhood Research Quarterly, 11, 269-306.

NICHD. (2000). The interaction of child care and family risk in relation to child development at 24 and 36 months. Applied Developmental Science, 6(3), 144156.

NICHD. (2003b). Does Quality of Child Care Affect Child Outcomes at Age 4 1/2? Developmental Psychology, 39(3), 451-469.

NICHD. (2003a). Modeling the impacts of child care quality on children's preschool cognitive development. Child Development, 74(5), 1454-1475.

Reynolds, A. J., \& Ou, S. (2003). Promoting Resilience through Early Childhood Intervention. In S. S. Luthar (Ed.), Resilience and Vulnerability: Adaptation in the Context of Childhood Adversity. Cambridge: Cambridge University Press.

Rose, B., Holmbeck, G., Coakley, R., \& Franks, E. (2004). Mediator and moderator effects in developmental and behavioral pediatric research. Journal of Developmental and Behavioral Pediatrics, 25, 1-10.

Rutter, M. (1987). Psychosocial Resilience and Protective Mechanisms. American Journal of Orthopsychiatry, 57(3), 316-331.

Sameroff, A. J., Gutman, L. M., \& Peck, S. C. (2003). Adaptation among Youth Facing Multiple Risks. In S. S. Luthar (Ed.), Resilience and Vulnerability: Adaptation in the Context of Childhood Adversities (pp. 364-391). Cambridge: Cambridge University Press.

Sameroff, A. J., Seifer, R., Baldwin, A., \& Baldwin, C. (1993). Stability of Intelligence from Preschool to Adolescence: The Influence of Social and Family Risk Factors. Child Development, 64(1), 80-97.

Sammons, P., Sylva, K., Melhuish, E., Siraj-Blatchford, I., Taggart, B., Grabbe, Y., et al. (2007). Effective Pre-School And Primary Education 3-11 project (EPPE 3-11): Influences on children's attainment and progress in Key Stage 2: cognitive outcomes in Year 5: Department for Education and Skills.

Sammons, P., Sylva, K., Melhuish, E., Siraj-Blatchford, I., Taggart, B., \& Elliot, K. (2002). EPPE Technical Paper 8a: Measuring the impact of Pre-school on Children's Cognitive Progress over the Pre-school Period. London: DfES/Institute of Education.

Sammons, P., Sylva, K., Melhuish, E., Siraj-Blatchford, I., Taggart, B., Hunt, S., et al. (2008). Effective Pre-School and Primary Education 3-11 Project (EPPE 311), Influences on Children's Cognitive and Social Development in Year 6. London: DfES/Institute of Education 
Sammons, P., Sylva, K., Melhuish, E., Siraj-Blatchford, I., Taggart, B., Smees, R., et al. (1999). EPPE Technical Paper 2: Characteristics of the EPPE Project Sample at Entry to the Study. London: DfES/Institute of Education.

Sammons, P., Taggart, B., Smees, R., Sylva, K., Melhuish, E., Siraj-Blatchford, I., et al. (2002). EYTSEN Technical Paper 1: Special Educational Needs across the Pre-School Period. London: DfES/Institute of Education.

Schoon, I., Bynner, J., Joshi, H., Parsons, S., Wiggins, R. D., \& Sacker, A. (2002). The influence of context, timing and duration of risk experiences for the passage from childhood to mid adulthood. Child Development, 73(5), 14861504.

Siraj-Blatchford, I., Sylva, K., Melhuish, E., Sammons, P., Taggart, B. \& Jennings. R. (1999), Technical Paper 3 - The Effective Provision of Pre-School Education (EPPE) Project: Contextualising EPPE: Interviews with local authority co ordinators and centre managers. London: DfEE / Institute of Education, University of London

Stipek, D. J., Feiler, R., Byler, P., Ryan, R., Milburn, S., \& Salmon, J. M. (1998). Good Beginnings: What Difference Does the Program Make in Preparing Young Children for School? Journal of Applied Developmental Psychology, 19(1), 41-66.

Sylva, K. (2000). Early Childhood Education to Ensure a 'Fair Start' for All. In T. Cox (Ed.), Combating Educational Disadvantage. Meeting the Needs of Vulnerable Children London: Falmer Press.

Sylva, K., Melhuish, E., Sammons, P., Siraj-Blatchford, I., \& Taggart, B. (2004). EPPE Technical Paper 12: Effective Provision of Pre-school Education, The Final Report. London: DfES/Institute of Education.

Sylva, K., Sammons, P., Taggart, B., Siraj-Blatchford, I., Melhuish, E., \& Hall, J. E. (2006). Tracking children with SEN through the Early Years: Can education make a difference?, 23rd Vernon-Wall Lecture: The British Psychology Society: Education Section.

Sylva, K., Siraj-Blatchford, I., Melhuish, E., Sammons, P., Taggart, B., Evans, E., et al. (1999). EPPE Technical Paper 6: Characteristics of the Centres in the EPPE Sample: Observational Profiles. London: DfES/Institute of Education.

Sylva, K., Siraj-Blatchford, I., \& Taggart, B. (2006). Assessing Quality in the Early Years: Early Childhood Environment Rating Scale. Extension (ECERS-E) Four Curricular Subscales. Revised Edition. Stoke On Trent: Trentham Books.

Sylva, K., Siraj-Blatchford, I., Taggart, B., Sammons, P., Melhuish, E., Elliot, K., et al. (2006). Capturing quality in early childhood through environmental rating scales. Early Childhood Research Quarterly. 21(1), 76-92.

Tabachnick, B. G., \& Fidell, L. S. (2001). Using multivariate statistics (4th ed.). Boston: Allyn and Bacon.

Tunstill, J., Allnock, D., Akhurst, S., \& Garbers, C. (2005). Sure Start Local Programmes: Implications of Case Study Data from the National Evaluation of Sure Start. Children \& Society, 19, 158-171.

Vandell, D. L., \& Wolfe, B. (2000). Child care quality: does it matter and does it need to be improved? Special Report No. 78, University of Wisconsin, Madison: Institute for Research on Poverty.

Villalón, M., Suzuki, E., Herrera, M. O., \& Mathiesen, M. E. (2002). Quality of Chilean Early Childhood Education from an International Perspective. International Journal of Early Years Education, 10(1), 49-59. 
Wu, A. D., \& Zumbo, B. D. (2007). Understanding and Using Mediators and Moderators. Social Indicators Research: An International Interdisciplinary Journal for Quality of Life Measurement.

Yates, T. M., Egeland, B., \& Sroufe, A. (2003). Rethinking Resilience: A Developmental Process Perspective. In S. S. Luthar (Ed.), Resilience and Vulnerability: Adaptation in the Context of Childhood Adversity (pp. 243265). Cambridge: Cambridge University Press.

Yuan, K. H., \& Bentler, P. M. (2000). Three Likelihood-Based Methods for Mean and Covariance Structure Analysis with Nonnormal Missing Data. Sociological Methodology, 30, 165-200. 


\section{Child}

1 Male gender (Rutter, 1987)

2 “English as an additional language (EAL)?” (Fawcett \& Lynch, 2000)

3 Birth weight (Hack et al., 2002)

4 Number of siblings (Sameroff, Gutman, \& Peck, 2003)

5 Birth order (Daniel \& Wassell, 2005)

6 Ethnicity (Sameroff, Gutman, \& Peck, 2003)

7 “Any event affected your child's development?"

\section{Familial}

1 Family salary (Yates, Egeland, \& Sroufe, 2003)

.气. 2 Mother's occupational status (Matthijs, 1994)

츄 3 Partner's occupational status (Matthijs, 1994)

4 "Highest status in family?" (Sameroff, Gutman, \& Peck, 2003)

5 Mother's qualifications (Sameroff, Gutman, \& Peck, 2003)

6 Partner's qualifications (Hernandez, 1997)

7 “Mother working?" (Brooks-Gunn, Han, \& Waldfogel, 2002)

8 “Partner working?" (Marsiglio, Amato, Day, \& Lamb, 2000)

9 “Either parent working?" (Hernandez, 1997)

1 “Two parent family?” (Yates, Egeland, \& Sroufe, 2003)

찰 $\stackrel{\mathscr{S}}{=} 2$ Mother's age (Johnson \& Waldfogel, 2002)

‘)

II 4 No. of non-parental carers (Johnson \& Waldfogel, 2002)

5 Home Learning Environment (HLE) (Sammons et al., 2002) 
Table 2. The child level risks to young children's cognitive development

\begin{tabular}{|c|c|c|c|}
\hline Variable & $\mathrm{n}$ & mean & $\begin{array}{l}\text { standard } \\
\text { deviation }\end{array}$ \\
\hline 1 Child's gender & 2857 & 0.48 & 0.50 \\
\hline Male (0) & 1489 & & \\
\hline Female (1) & 1368 & & \\
\hline 2 "English as an additional language (EAL)?" & 2857 & 0.08 & 0.28 \\
\hline English (0) & 2622 & & \\
\hline not English (1) & 235 & & \\
\hline 3 Birth weight (in grams) & 2752 & 3315.98 & 624.22 \\
\hline 4 Number of siblings & 2786 & 1.38 & 1.11 \\
\hline 5 Birth order & 2783 & 1.83 & 0.98 \\
\hline 6 Ethnicity & 2854 & & \\
\hline Bangladeshi & 25 & & \\
\hline Black & 180 & & \\
\hline Indian & 55 & & \\
\hline Pakistani & 75 & & \\
\hline Mixed & 185 & & \\
\hline Other & 89 & & \\
\hline White & 2245 & & \\
\hline 7 “Any event affected your child's development?" & 2783 & 0.34 & 0.47 \\
\hline No $(0)$ & 1838 & & \\
\hline $\operatorname{Yes}(1)$ & 945 & & \\
\hline
\end{tabular}


Table 3. The familial level risks to young children's cognitive development

\begin{tabular}{|c|c|c|c|}
\hline Variable & $\bar{n}$ & mean & standard deviation \\
\hline 1 Family Salary & 2178 & 27495.41 & 25875.04 \\
\hline 2 Mother's occupational status (reversed) & 2744 & 3.59 & 1.68 \\
\hline Professional non manual (1) & 123 & & \\
\hline Other professional non manual (2) & 589 & & \\
\hline Skilled non manual (3) & 1018 & & \\
\hline Skilled manual (4) & 178 & & \\
\hline Semi skilled (5) & 549 & & \\
\hline Unskilled (6) & 122 & & \\
\hline Unemployed (7) & 0 & & \\
\hline Never worked (8) & 165 & & \\
\hline 3 Partner's occupational status (reversed) & 2174 & 3.26 & 1.43 \\
\hline 4 "Highest status in family?" (reversed) & 2781 & 2.08 & 1.38 \\
\hline 5 Mother's qualifications & 2723 & 1.98 & 1.40 \\
\hline None (0) & 501 & & \\
\hline Vocational (1) & 423 & & \\
\hline 16 Academic (2) & 1048 & & \\
\hline 18 Academic (3) & 248 & & \\
\hline Degree or equivalent (4) & 374 & & \\
\hline High Degree (5) & 129 & & \\
\hline 6 Partner's qualifications & 2073 & 2.15 & 1.55 \\
\hline 7 Mother employment status & 2780 & 0.77 & 0.88 \\
\hline Unemployed (0) & 1344 & & \\
\hline Employed part time (1) & 861 & & \\
\hline Self employed and employed part time & 448 & & \\
\hline Employed full time (3) & 127 & & \\
\hline 8 Partner employment status & 2183 & 2.37 & 1.06 \\
\hline 9 "Either parent working?" & 2178 & 1.89 & 1.21 \\
\hline No one working in the house $(0)$ & 471 & & \\
\hline Mum working and partner not (1) & 314 & & \\
\hline Mother's partner working and mother & & & \\
\hline $\operatorname{not}(2)$ & 373 & & \\
\hline Both mother and partner working (3) & 1020 & & \\
\hline 10 "Two parent family?" & 2790 & 0.75 & 0.43 \\
\hline No $(0)$ & 698 & & \\
\hline Yes (1) & 2076 & & \\
\hline 11 Mother's age group & 2779 & 3.16 & 0.66 \\
\hline $16-20(1)$ & 22 & & \\
\hline $21-25(2)$ & 310 & & \\
\hline $26-35(3)$ & 1697 & & \\
\hline $36-45(4)$ & 721 & & \\
\hline $46-55(5)$ & 22 & & \\
\hline $56-65(6)$ & 7 & & \\
\hline $66-75(7)$ & 0 & & \\
\hline 12 Partner's age group & 2218 & 3.47 & 0.68 \\
\hline 13 No. of non-parental carers & 2794 & 1.06 & 1.05 \\
\hline 14 Home Learning Environment (HLE) & 2748 & 23.42 & 7.6 \\
\hline
\end{tabular}


Table 4. Standardised factor loadings and impacts of individual child and familial level risks (2 d.p.)

\begin{tabular}{|c|c|c|c|}
\hline \multirow[b]{2}{*}{ Risk Variable } & \multicolumn{3}{|c|}{ Standardized Regression coefficients $(\beta)$} \\
\hline & $\begin{array}{l}\text { Risk Factor } \\
\text { Loadings }\end{array}$ & $\begin{array}{l}\text { Impact on } \\
\text { GCA at entry } \\
\text { to pre-school }\end{array}$ & $\begin{array}{l}\text { Impact on } \\
\text { GCA at entry } \\
\text { to reception }\end{array}$ \\
\hline Latent Child Level Risk & & $-0.38 * * *$ & $-0.11 * * *$ \\
\hline Male gender & $0.28 * * *$ & & \\
\hline EAL? & $0.48^{\mathrm{a}}$ & & \\
\hline Birth weight & $-0.37 * * *$ & & \\
\hline No. of siblings & $0.25 * *$ & & \\
\hline Birth order & 0.12 & & \\
\hline Bangladeshi? & $0.12 *$ & & \\
\hline Black? & $0.25 * * *$ & & \\
\hline Indian? & 0.01 & & \\
\hline Mixed ethnicity? & $0.14 * *$ & & \\
\hline Other ethnicity? & 0.09 & & \\
\hline Pakistani? & $0.31 * *$ & & \\
\hline $\begin{array}{l}\text { "Any event affected your } \\
\text { child's development?" }\end{array}$ & -0.03 & & \\
\hline Latent Familial Level Risk & & $-0.52 * * *$ & $-0.23 * * *$ \\
\hline Family salary & $-0.17 * *$ & & \\
\hline $\begin{array}{l}\text { Mother's occupational status } \\
\text { (reversed) }\end{array}$ & $-0.19 * *$ & & \\
\hline $\begin{array}{l}\text { Partner's occupational status } \\
\text { (reversed) }\end{array}$ & -0.10 & & \\
\hline $\begin{array}{l}\text { "Highest status in family?" } \\
\text { (reversed) }\end{array}$ & -0.01 & & \\
\hline Mother's qualifications & $-0.25 * * *$ & & \\
\hline Partner's qualifications & 0.00 & & \\
\hline "Mother working?" & 0.02 & & \\
\hline "Partner working?" & $-0.09 *$ & & \\
\hline "Either parent working?" & -0.08 & & \\
\hline "Two parent family?" & 0.02 & & \\
\hline Mother's age & -0.08 & & \\
\hline Partner's age & 0.02 & & \\
\hline No. of non-parental carers & $-0.14 * * *$ & & \\
\hline HLE & $-0.45^{\mathrm{a}}$ & & \\
\hline
\end{tabular}


Table 5. Direct and Risk Moderating Effects of Pre-school Provision on General Cognitive Ability at entry to reception (2 d.p.)

\begin{tabular}{lcc}
\hline & \multicolumn{2}{c}{ UnStandardised Beta Regression Coefficients } \\
Pre-school process quality & Child level Risk & Familial level Risk \\
\hline & Direct effects \\
ECERS-R & 0 & -0.01 \\
ECERS-E & 0.04 & -0.01 \\
Positive Relationship & 0.04 & -0.01 \\
Punitiveness & -0.04 & -0.11 \\
Permissiveness & $\mathbf{- 0 . 0 5 *}$ & -0.03 \\
Detachment & $\mathbf{- 0 . 0 6 * *}$ & -0.01 \\
\hline & Risk moderating effects & \\
ECERS-R & 0.02 & $\mathbf{0 . 0 3} * * *$ \\
ECERS-E & $\mathbf{0 . 0 2 *}$ & $\mathbf{0 . 0 3} * * *$ \\
Positive Relationship & $\mathbf{0 . 0 4 *}$ & 0.01 \\
Punitive & -0.01 & -0.01 \\
Permissive & 0 & -0.01 \\
Detachment & $\mathbf{- 0 . 0 3 *}$ & -0.01 \\
\hline \hline
\end{tabular}


Figure 1. Path diagram illustrating the multi-level Structural Equation Models used in this investigation (stylised)

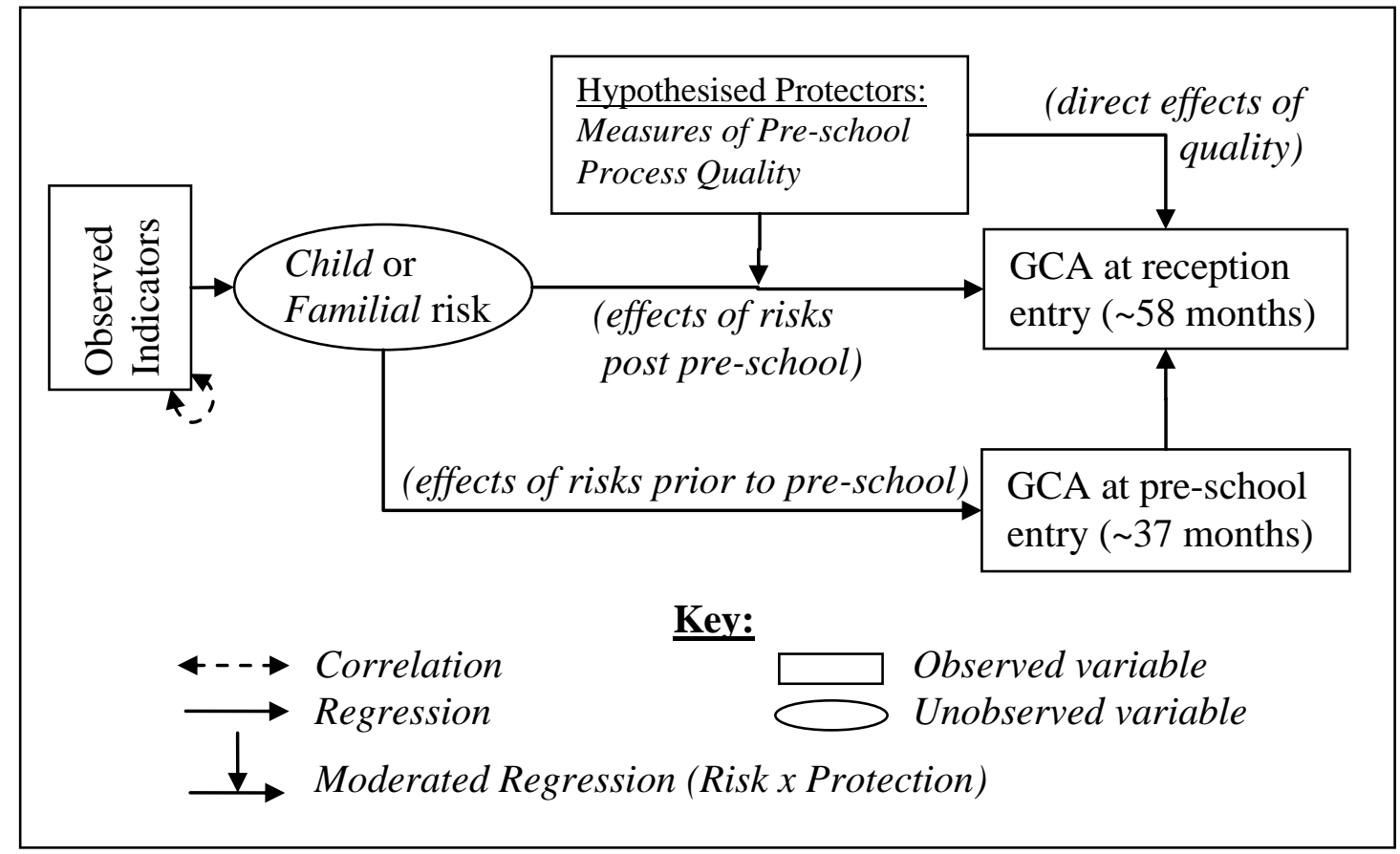


Figure 2. Differentiated (moderated) impact of child level risk on GCA at entry to reception: Protection conferred by process qualities of pre-school

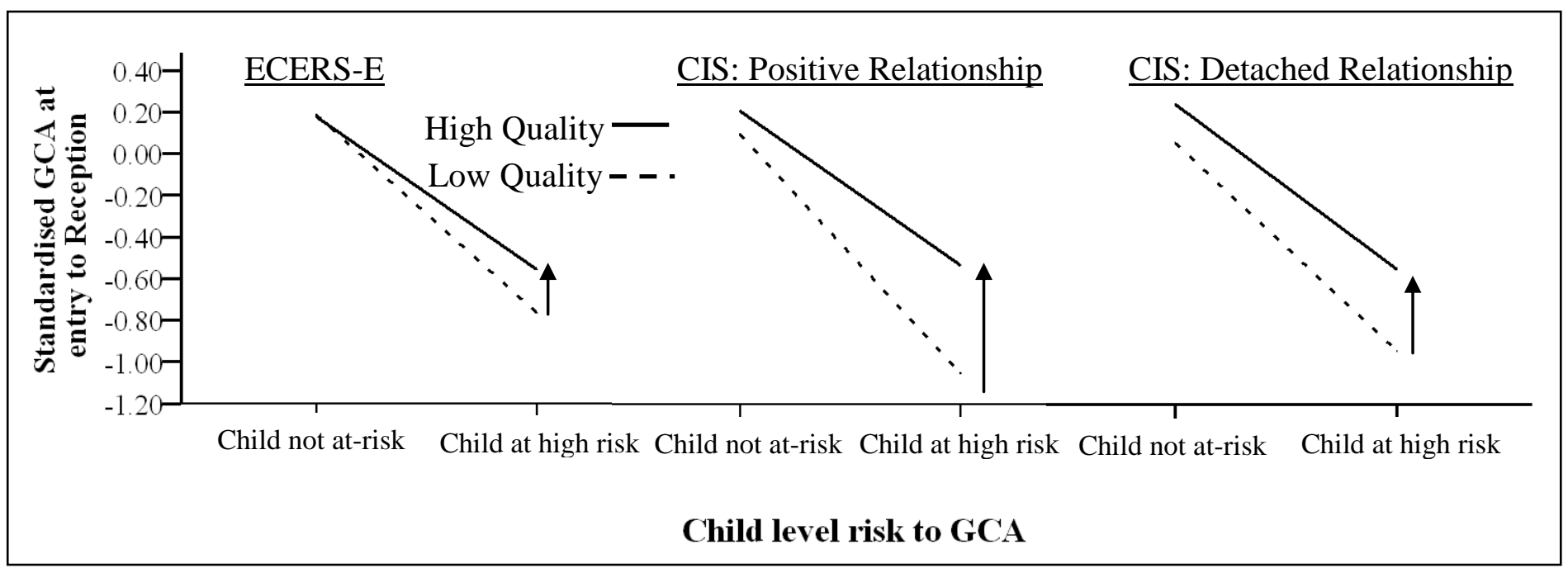


Figure 3. Differentiated (moderated) impact of familial level risk on GCA at entry to reception: Protection conferred by process qualities of pre-school

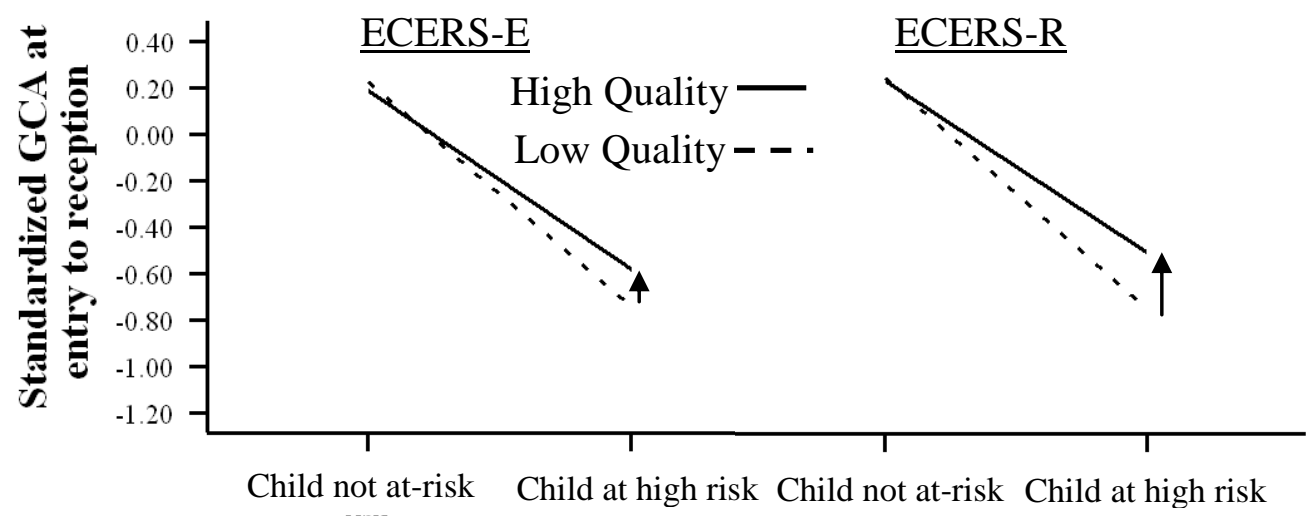

Familial level risk to GCA 